\title{
A RETROSPECTIVE STUDY OF COMMON DISEASES AT VETERINARY TEACHING HOSPITAL, BANGLADESH AGRICULTURAL UNIVERSITY, MYMENSINGH
}

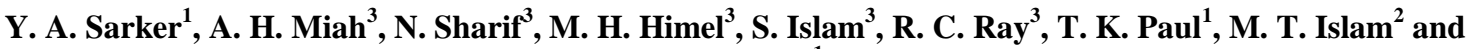 \\ M. H. Sikder ${ }^{1 *}$ \\ ${ }^{1}$ Department of Pharmacology, Bangladesh Agricultural University, Mymensingh-2202, Bangladesh; ${ }^{2}$ Department of \\ Medicine, Bangladesh Agricultural University, Mymensingh-2202, Bangladesh; ${ }^{3}$ Department of Surgery and \\ Obstetrics, Bangladesh Agricultural University, Mymensingh-2202, Bangladesh
}

\begin{abstract}
A retrospective study was undertaken to determine the occurrence and distribution of diseases based on species, age, sex, system affected, case type, causal agents and season variation at Veterinary Teaching Hospital, Bangladesh Agricultural University from January 2012 to December 2014. According to the case record, a total of 5036 sick animals were examined and 103 types of diseases were identified during this period. The commonly found various diseases were parasitic disease $(33.86 \%)$, myiasis $(5.96 \%)$, PPR $(5.16 \%)$, pneumonia and pneumonitis $(4.11 \%)$, repeat breeding $(2.88 \%)$ and rest of the diseases had lower percentage than $2.5 \%$. Out of the 5036, 1759 cases $(35 \%)$ were male and 3277 cases $(65 \%)$ were female. Animals aged between 1-3 years had high occurrence (45.23\%) followed by $0-1$ year $(25.11 \%)$. Diseases in digestive system were mostly affected (33.79\%) and lowest in cardiovascular system $(0.65 \%)$. Occurrence of diseases was highest $(36.81 \%)$ in rainy season (June-October) followed by (35.54\%) in summer (March-May) and lowest (27.64\%) in winter season (November-February). The findings of this study can be used in the formulation of more effective disease management and control strategies including appropriate vaccination program in this area.
\end{abstract}

Keywords: Retrospective study, epidemiology, prevalence, veterinary teaching hospital

\section{INTRODUCTION}

Agriculture consisting of crop, fisheries, livestock and forest sub sector continues to be the largest sector of Bangladesh economy. Livestock sub sector contributes 12\% to agricultural GDP and 3\% to National economy (Mia, 2013). Livestock subsector provides new raw material for industry, serves a social security for the rural poor, and provides security against crop failure or damage during draught or cyclone. Though Bangladesh has one of the highest livestock populations in the world, but characterized by very low productivity, particularly in cattle because of low productivity, inferior genetic material, indiscriminate breeding leading to severe genetic erosion, neglect of animal healthcare and non- existence of an efficient value chain, shortage of feeds and fodder resources and lack of awareness (BIDS, 2012).

However, more than 10 million people directly depend on these sectors for their livelihoods (Karim et al., 2010). The management practices of animals and geo-climatic condition of Bangladesh are favorable for the occurrence of various diseases (Onneshan, 2014). Veterinary hospital is an ideal and reliable source of information about animal diseases with their treatment. People from the neighboring areas bring their sick animals to the Veterinary hospital every day. Analysis of the case record gives a comprehensive idea about the disease problems at local areas. Although some reports on clinical case records from Bangladesh Agricultural University Veterinary Teaching Hospital (Das and Hashim, 1996; Samad, 2001; Samad et al., 2002; Sarker et al., 2013; Ali et al., 2011), Haluaghat Upazilla Veterinary Hospital, Mymensingh (Sarker et al., 1999) and Dairy Cooperatives in Pabna district (Pharo, 1987), Ulipur Upazilla Veterinary Hospital, Kurigram (Kabir et al., 2010), Chandanaish Upazilla of Chittagong district, Bangladesh (Pallab et al., 2012) and Patuakhali Science and Technology University Veterinary Clinic (Rahman et al., 2012) are available but no study was performed after 2002 in Veterinary Teaching Hospital, Bangladesh Agricultural University, Mymensingh.

The objectives were to determine occurrence of diseases and disorders in animals attended in Veterinary Teaching Hospital, BAU including the distribution of diseases based on species, age, sex, system affected, case type, causal agents and season variation from January 2012 to December 2014.

*Corresponding e-mail address: drmsikder@bau.edu.bd

Copyright (c) 2015 Bangladesh Society for Veterinary Medicine

All rights reserved 0339/2015 


\section{Y. A. Sarker and others}

\section{MATERIALS AND METHODS}

The retrospective epidemiologic study of diseases was done using 3 years data at Veterinary Teaching Hospital (VTH) of Bangladesh Agricultural University, Mymensingh. The retrospective data of 3 years from January 2012 to December 2014 were collected from patient case record of Veterinary Teaching Hospital, Bangladesh Agricultural University, Mymensingh. The data were analyzed retrospectively and interpreted to determine the occurrence of diseases; seasonal pattern and distribution of diseases. The patient's data were collected from the register book after official permission from the director of the veterinary teaching hospital. During the period of study 5036 diseased animals were recorded from patient register.

The data were manually patterned for recording errors or missing data and obvious discrepancies. The potential errors were assessed and corrected. Data with apprehensive values were excluded. Data were statistically analyzed by Epi Info software 3.5.3 version and Statistical Package for Social Science (SPSS) software 20 version. Chi-square test was used to know the association between different groups in respective cases. According to age, diseased animals were grouped as based on terminology. We considered three seasons according to Ali et al. (2011) as summer from March to May, rainy from June to October and winter from November to February.

These recorded clinical cases were primarily categorized into three major groups on the basis of treatment required. These groups were: (1) Medicinal cases, (2) Gynaeco-obstetrical cases and (3) Surgical cases. In case of multiple system affection two or more systems were affected namely digestive, respiratory and/or integumentary system. However, the eye diseases which also include corneal opacity were included under medicinal cases because surgical intervention has never been practiced in Bangladesh (Osmani et al., 2000).

\section{RESULTS AND DISCUSSION}

In total of 5036 cases; 1079 cases $(21.4 \%)$ were cow, 481 cases $(9.5 \%)$ were bull, 1155 cases $(22.9 \%)$ were heifer, 654 cases $(12.9 \%)$ were calf, 1450 cases $(28.8 \%)$ were goat, 15 cases $(0.3 \%)$ were sheep, 11 cases $(0.2 \%)$ were horse, 37 cases $(0.8 \%)$ were dog, 17 cases $(0.3 \%)$ were cat, 32 cases $(0.6 \%)$ were rabbit and 105 cases $(2.2 \%)$ were bird . Out of the 5036, 1759 cases (35\%) were male and 3277 cases $(65 \%)$ were female. Male and female animal's ratio was 1:2 approximately.

\section{Age, sex and season wise distribution of diseases and disorders observed in different systems of cattle}

The diseases and disorders observed in the different systems of cattle are shown in the Table 1. In the study 5036 animals were studied where cattle were 3361 and out of 103 detected diseases in different system about79 diseases were observed in case of cattle. System wise top 5 diseases are described in the Table 2. In the study it was found that cattle of different aged were suffering from various diseases and disorders, where maximum no. of cattle (964) was affected by parasitic infection. The study also revealed that most of cattle of all aged were affected with gastrointestinal diseases (Table 1). It was exerted from the study that myiasis also occurred as well as anestrus and repeat breeding were found in cattle. Worm infestation was more frequent in all the studied aged of cattle as compared with other diseases and disorders. Table 1 expressed that cattle of 1-3 years old were mostly affected by diseases and disorders in contrast of cattle of other age group.

Sex wise diseases and disorders in cattle were presented in the Table 1 . The study revealed that female cattle were significantly affected with diseases and disorder observed in the different systems of cattle where as male responded as less. Likely the trend of age based phenomena; worm infestation was also ranked as the most frequent in case of female in the studied areas due to less attention against preventing measures of worm as described as Rahman et al. (2012). 
Table 1. Systemic distribution of diseases in cattle observed in age, sex and season wise

\begin{tabular}{lllllllllll}
\hline & \multicolumn{3}{c}{ Age group (year) } & \multicolumn{3}{c}{ Sex } & \multicolumn{5}{c}{ Season } \\
\cline { 2 - 8 } Systems involved & $0-1$ & $1-3$ & $3-8$ & $8-15$ & T & F & Summer & Rainy & Winter & Total \\
& $\left(\mathrm{A}_{1}\right)$ & $\left(\mathrm{A}_{2}\right)$ & $\left(\mathrm{A}_{3}\right)$ & $\left(\mathrm{A}_{4}\right)$ & & & & & & \\
\hline Gastrointestinal & 125 & 305 & 425 & 265 & 401 & 719 & 392 & 414 & 314 & 1120 \\
Respiratory & 42 & 85 & 51 & 21 & 73 & 126 & 69 & 74 & 56 & 199 \\
Reproductive & 0 & 125 & 179 & 160 & 75 & 389 & 162 & 172 & 130 & 464 \\
Integumentary & 190 & 155 & 75 & 56 & 152 & 324 & 166 & 176 & 134 & 476 \\
Musculo-skeletal & 35 & 66 & 45 & 26 & 63 & 109 & 61 & 64 & 47 & 172 \\
Hematopoietic & 30 & 49 & 43 & 10 & 46 & 86 & 46 & 49 & 37 & 132 \\
Urinary & 35 & 25 & 30 & 12 & 37 & 65 & 36 & 38 & 28 & 102 \\
Nervous & 37 & 21 & 7 & 0 & 25 & 40 & 23 & 24 & 18 & 65 \\
Cardiovascular & 17 & 11 & 5 & 0 & 15 & 18 & 12 & 12 & 9 & 33 \\
Multiple system & 143 & 313 & 125 & 25 & 214 & 392 & 212 & 224 & 170 & 606 \\
Total & 654 & 1155 & 985 & 575 & 1101 & 2268 & 1179 & 1247 & 943 & 3369 \\
\hline
\end{tabular}

There is statistically significant relation between diseases and ages of cattle $\left(\chi^{2}=379.701\right)$, disease and sex $\left(\chi^{2}\right.$ $=404.241)$ and disease and season $\left(\chi^{2}=45.336\right)$.

Table 2. Top five (5) diseases/disorders in cattle

\begin{tabular}{llll}
\hline Name of the disease/disorder & Male & Female & Total \\
\hline Liver and rumen fluke infestations & 230 & 431 & 661 \\
Ectoparasitic infestation & 115 & 188 & 303 \\
Myiasis & 53 & 99 & 152 \\
Balantidiasis & 50 & 88 & 138 \\
Repeat Breeding & 0 & 129 & 129 \\
Total & 448 & 935 & 1383 \\
\hline
\end{tabular}

Season wise diseases and disorders in cattle were presented in the Table 1 . The results obtained from the study exerted that diseases and disorders of cattle were more prominent in the rainy season $(37.02 \%)$ than that of summer $(34.99 \%)$ and winter $(27.99 \%)$ ones. According to Islam et al. (2012b) vectors of different internal and external parasites were more prevalent due to geo-climatic condition of studied area so that parasitic diseases are more prominent. Among the reproductive diseases repeat breeding is more common due to heat detection error and improper timing of AI in cow as described in Khair et al. (2013).

\section{Age, sex and season wise distribution of diseases and disorders observed in different systems of goat}

Age, sex and season wise distribution of diseases and disorders in goat as per systems have been summarized and presented in Table 3.In the study 5036 animals were studied where goats were 1450 and System wise top 5 diseases are described in Table 4. In the study it was found that goat of different aged were significantly suffering from various diseases and disorders, where maximum no. of goat $(\mathrm{n}=223)$ were affected by Peste des petits ruminants (PPR).

Highest diseases were found in age group A2 includes one to three years of age (Table 3). The diseases of gastrointestinal system were commonly found in female $(n=217)$ than that of male $(n=117)$. Diseases of goat related with season shown that most of the diseases occurred during the rainy season than that of summer and winter (Table 3).

Goats were mostly affected with PPR $(n=223)$ due to its contagious nature and vaccinated goats also affected with it as described by Islam et al. (2012a). Causes of myiasis and parasitic infection previously described due to geo-climatic condition. 


\section{Y. A. Sarker and others}

Table 3. Systemic distribution of diseases in goat observed in age, sex and season wise

\begin{tabular}{|c|c|c|c|c|c|c|c|c|c|}
\hline \multirow{2}{*}{ System involved } & \multicolumn{3}{|c|}{ Age group (year) } & \multicolumn{2}{|c|}{ Sex } & \multicolumn{3}{|c|}{ Season } & \multirow[b]{2}{*}{ Total } \\
\hline & $\begin{array}{l}0-1 \\
\text { (A1) }\end{array}$ & $\begin{array}{l}1-3 \\
\text { (A2) }\end{array}$ & $\begin{array}{l}3-8 \\
\text { (A3) }\end{array}$ & M & $\mathrm{F}$ & Summer & Rainy & Winter & \\
\hline Gastrointestinal & 120 & 157 & 57 & 117 & 217 & 117 & 124 & 93 & 334 \\
\hline Respiratory & 52 & 68 & 25 & 51 & 94 & 51 & 54 & 40 & 145 \\
\hline Reproductive & 3 & 165 & 35 & 71 & 132 & 70 & 74 & 58 & 203 \\
\hline Integumentary & 73 & 95 & 35 & 71 & 132 & 71 & 74 & 58 & 203 \\
\hline Musculo-skeletal & 26 & 34 & 12 & 25 & 47 & 25 & 27 & 20 & 72 \\
\hline Hematopoietic & 21 & 27 & 10 & 20 & 38 & 20 & 22 & 17 & 58 \\
\hline Urinary & 31 & 41 & 15 & 30 & 57 & 31 & 32 & 24 & 87 \\
\hline Nervous & 31 & 41 & 15 & 30 & 57 & 31 & 32 & 24 & 87 \\
\hline Cardiovascular & 0 & 0 & 0 & 0 & 0 & 0 & 0 & 0 & 0 \\
\hline Multiple system & 94 & 123 & 44 & 91 & 170 & 91 & 97 & 73 & 261 \\
\hline Total & 451 & 751 & 290 & 526 & 924 & 507 & 536 & 407 & 1450 \\
\hline
\end{tabular}

Table 4. Top five (5) diseases/disorders in goat

\begin{tabular}{llll}
\hline Name of the disease/disorder & Male & Female & Total \\
\hline PPR & 89 & 134 & 223 \\
Pneumonia & 48 & 84 & 132 \\
Myiasis & 32 & 57 & 89 \\
Parasitic infestation & 22 & 33 & 55 \\
Fracture & 17 & 26 & 43 \\
Total & 208 & 334 & 542 \\
\hline
\end{tabular}

Age, sex and season wise distribution of diseases and disorders observed in different systems of sheep

Age, sex and season wise distribution of diseases and disorders in sheep as per systems have been summarized and presented (Table 5). Mostly digestive system is affected by parasitic infection and the following is musculoskeletal system by myiasis and gangrene. Diseases and disorders are more prevalent in female than male and in rainy season sheep's are mostly affected rather than summer and winter.

Table 5. Systemic distribution of diseases in sheep observed in age, sex and season wise

\begin{tabular}{|c|c|c|c|c|c|c|c|c|c|}
\hline \multirow{2}{*}{$\begin{array}{l}\text { Diseases occurred in } \\
\text { different systems }\end{array}$} & \multicolumn{3}{|c|}{ Age group (year) } & \multicolumn{2}{|c|}{ Sex } & \multicolumn{3}{|c|}{ Season } & \multirow[b]{2}{*}{ Total } \\
\hline & $\begin{array}{l}0-1 \\
(\mathrm{~A} 1) \\
\end{array}$ & $\begin{array}{l}1-3 \\
\text { (A2) } \\
\end{array}$ & $\begin{array}{l}3-8 \\
\text { (A3) } \\
\end{array}$ & M & $\mathrm{F}$ & Summer & Rainy & Winter & \\
\hline Gastrointestinal system & & & & & & & & & 6 \\
\hline Anorectic syndrome & 0 & 1 & 0 & 1 & 0 & 0 & 1 & 0 & \\
\hline Parasitic infestation & 1 & 3 & 1 & 2 & 3 & 1 & 3 & 1 & \\
\hline Respiratory system & & & & & & & & & \\
\hline Pneumonia & 1 & 0 & 0 & 0 & 1 & 0 & 0 & 1 & 1 \\
\hline Reproductive system & & & & & & & & & 3 \\
\hline Dystocia & 0 & 2 & 1 & 0 & 3 & 1 & 2 & 0 & \\
\hline Musculo-skeletal system & & & & & & & & & 5 \\
\hline Gangrene & 1 & 1 & 0 & 2 & 0 & 2 & 0 & 0 & \\
\hline Myiasis & 1 & 1 & 1 & 1 & 2 & 2 & 1 & 0 & \\
\hline Total & 5 & 7 & 3 & 6 & 9 & 6 & 7 & 2 & 15 \\
\hline
\end{tabular}


Age, sex and season wise distribution of diseases and disorders observed in different systems of horse

Diseases and disorders in horse are described in the Table 6 according to age group, sex and season. Most diseases are occurred in A2 and A3 age group. Diseases and disorders are more common in male (64\%) than female $(36 \%)$ because of male are used in racing and carrying purpose.

Table 6. Systemic distribution of diseases in horse observed in age, sex and season wise

\begin{tabular}{|c|c|c|c|c|c|c|c|c|c|}
\hline \multirow{2}{*}{$\begin{array}{l}\text { Diseases occurred in } \\
\text { different systems }\end{array}$} & \multicolumn{3}{|c|}{ Age group (year) } & \multicolumn{2}{|c|}{ Sex } & \multicolumn{3}{|c|}{ Season } & \multirow[b]{2}{*}{ Total } \\
\hline & $\begin{array}{l}0-1 \\
(\mathrm{~A} 1)\end{array}$ & $\begin{array}{l}1-3 \\
(\mathrm{~A} 2)\end{array}$ & $\begin{array}{l}3-8 \\
\text { (A3) }\end{array}$ & $\mathrm{M}$ & $\mathrm{F}$ & Summer & Rainy & Winter & \\
\hline Gastrointestinal & & & & & & & & & 4 \\
\hline Colic & 0 & 1 & 1 & 1 & 1 & 1 & 1 & 0 & \\
\hline $\begin{array}{l}\text { Parasitic infestation } \\
\text { Musculo-skeletal }\end{array}$ & 0 & 1 & 1 & 1 & 1 & 1 & 1 & 0 & \\
\hline Abscess & 1 & 1 & 1 & 2 & 1 & 2 & 1 & 0 & 7 \\
\hline Wound & 0 & 1 & 1 & 2 & 0 & 1 & 1 & 0 & \\
\hline Fracture & 0 & 1 & 1 & 1 & 1 & 0 & 1 & 1 & \\
\hline Total & 1 & 5 & 5 & 7 & 4 & 5 & 5 & 1 & 11 \\
\hline
\end{tabular}

Age, sex and season wise distribution of diseases and disorders observed in different systems of dog

Diseases and disorders in dogs according to age group, sex and season are described (Table 7). Most diseases are occurred in A1 and A2 age group. Diseases and disorders are more common in male (63\%) than female $(37 \%)$ because of male are used as pet animal after castration. Dermatitis was the most common cases $(34 \%)$ were seen during study period. Six rabid dogs (16\%) were found during the study period at VTH, BAU.

Table 7. Systemic distribution of diseases in dog observed in age, sex and season wise

\begin{tabular}{|c|c|c|c|c|c|c|c|c|c|}
\hline \multirow[b]{2}{*}{$\begin{array}{l}\text { Diseases occurred in } \\
\text { different systems }\end{array}$} & \multicolumn{3}{|c|}{ Age group (year) } & \multicolumn{2}{|c|}{ Sex } & \multicolumn{3}{|c|}{ Season } & \multirow[b]{2}{*}{ Total } \\
\hline & $\begin{array}{l}0-1 \\
\text { (A1) }\end{array}$ & $\begin{array}{l}1-3 \\
\text { (A2) }\end{array}$ & $\begin{array}{l}3-8 \\
\text { (A3) }\end{array}$ & M & $\mathrm{F}$ & Summer & Rainy & Winter & \\
\hline Gastrointestinal & & & & & & & & & 12 \\
\hline Anorectic syndrome & 2 & 2 & 1 & 3 & 2 & 2 & 2 & 1 & \\
\hline Parasitic infestation & 2 & 3 & 2 & 4 & 3 & 2 & 4 & 1 & \\
\hline Musculo-skeletal & & & & & & & & & 7 \\
\hline Myiasis & 3 & 2 & 2 & 4 & 3 & 3 & 2 & 2 & \\
\hline Integument (Skin) & & & & & & & & & 12 \\
\hline Dermatitis & 5 & 4 & 3 & 8 & 4 & 4 & 5 & 3 & \\
\hline Rabid dog & 0 & 2 & 4 & 4 & 2 & 4 & 1 & 1 & 6 \\
\hline Total & 13 & 13 & 12 & 24 & 14 & 15 & 14 & 9 & 37 \\
\hline
\end{tabular}

Age, sex and season wise distribution of diseases and disorders observed in different systems of cat

Diseases and disorders in cats according to age group, sex and season are described (Table 8). Most diseases were occurred in A1 age group. Diseases and disorders are more common in male (59\%) than female (41\%) because of male are used as pet animal after castration. Gastrointestinal system was frequently affected by stomatitis $(35 \%)$ and anorectic syndrome (17\%). Stomatitis is frequently occurred due to eating of fish spine, edged bone also described in Healey et al. (2007). In rainy season $47 \%$ cases were placed than summer (42\%) and winter $(11 \%)$. 


\section{Y. A. Sarker and others}

Table 8. Systemic distribution of diseases in cat observed in age, sex and season wise

\begin{tabular}{|c|c|c|c|c|c|c|c|c|c|}
\hline \multirow[b]{2}{*}{$\begin{array}{l}\text { Diseases occurred in } \\
\text { different systems }\end{array}$} & \multicolumn{3}{|c|}{ Age group (year) } & \multicolumn{2}{|c|}{ Sex } & \multicolumn{3}{|c|}{ Season } & \multirow[b]{2}{*}{ Tota } \\
\hline & $\begin{array}{l}0-1 \\
\text { (A1) }\end{array}$ & $\begin{array}{l}1-3 \\
(\mathrm{~A} 2)\end{array}$ & $\begin{array}{l}3-8 \\
(\mathrm{~A} 3)\end{array}$ & M & $\mathrm{F}$ & Summer & Rainy & Winter & \\
\hline Gastrointestinal & & & & & & & & & 9 \\
\hline Stomatitis & 4 & 2 & 0 & 3 & 3 & 2 & 3 & 1 & \\
\hline Anorectic syndrome & 2 & 1 & 0 & 2 & 1 & 2 & 1 & 0 & \\
\hline Musculo-skeletal & & & & & & & & & 4 \\
\hline Myiasis & 1 & 1 & 0 & 2 & 0 & 1 & 1 & 0 & \\
\hline Wound & 1 & 1 & 0 & 1 & 1 & 1 & 1 & 0 & \\
\hline Dermatitis & 2 & 2 & 0 & 2 & 2 & 1 & 2 & 1 & 4 \\
\hline Total & 10 & 7 & 0 & 10 & 7 & 7 & 8 & 2 & 17 \\
\hline
\end{tabular}

Age, sex and season wise distribution of diseases and disorders observed in different systems of rabbit

Diseases and disorders in rabbit are described in according to age group, sex and season. Most diseases were occurred in A3 age group. Diseases and disorders are more common in male $(60.61 \%)$ than female $(39.39 \%)$ because of male are used as pet. Pasteurellosis (21.21\%) was most frequent among the diseases.

\section{Postmortem report of birds reported at VTH, BAU}

A total 106 number of birds were reported at VTH for diagnosis of disease/s by postmortem. Six types of diseases were found, among them Newcastle Disease (34.90\%) ranked top followed by salmonellosis (20.75\%), avian pox (16.98\%) and lowest was salmonellosis with mycoplasmosis (7.54\%). Newcastle Disease (ND) was mostly found in layer and pigeon.

\section{Temporal distribution of diseases}

Out of total 5036 cases highest cases were found in March (11.85\%) followed by July (11.60\%), August $(10.25 \%)$ and lowest in January (5.02\%). Disease frequency was highest in the starting of summer (March$11.85 \%$ ) and then rainy season (July-11.60\%). Due to climatic changes and presence of vector causes vectorborne diseases; in March occurrence of disease become high. In July because of geographic and temporal cluster disease occurrence also high. Occurrence of diseases and disorder in both month March and July high due to immunological status, travels, community behaviors of animal also similar reported by Samad (2011).

\section{Diseases of the reported animals at VTH, BAU}

Occurrence of diseases was classified mostly depends on systematic affections. This was done to find which system/s was/were affected and causes health disturbances. However, gastrointestinal system was mostly affected which was similar with Kabir et al. (2002), Ali et al. (2011) and Sarker et al. (2013). Among individual diseases the prevalence of parasitic infestation\&/ infection was highest followed by 6 diseases were more prevalent e.g. myiasis, repeat breeding, PPR, anorexia, pneumonia and balantidiasis. The prevalence of other diseases was comparatively low. Among diseases of different systems those affecting reproductive system constituted highest occurrence is repeat breeding followed by anestrous. This was due to mainly for nutritional deficiency, infectious diseases, ovarian cyst and failure to heat detection by owners as described by Khair et al. (2013). The prevalence of parasitic disease was $33.86 \%$ in the present study. The higher rates $51.50 \%$ had been recorded previously (Ali et al., 2011). This occurred due to improper following the anthelmintic schedule by animal owner which also described by Islam et al. (2012b). Among the postmortem cases of birds ND ranked top in layer and pigeon. More diseases were reported in the rainy season.

We recommend for undertaking retrospective research focusing on the causes of most predominant general, systemic and reproductive disorders of animals on regular basis which will help to identify risk factors of diseases. Control measure should be initiated to reduce the burden of these diseases/disorders in the study area. This study generated information which is valuable not only for the clinicians, researchers, animal health 
companies, policy planners, management and control strategy of diseases but also for the academicians to update veterinary curricula.

\section{ACKNOWLEDGEMENTS}

The authors are grateful to A. I. Mridul and W. J. Kona, Bangladesh Agricultural University, Mymensingh2202, Bangladesh for technical support.

\section{REFERENCES}

1. Ali MH, Bhuiyan MKJ and Alam MM (2011). Retrospective epidemiologic study of diseases in ruminants in Khagrachari Hill Tract District of Bangladesh. Bangladesh Journal of Veterinary Medicine 9: 145-153.

2. BIDS (2012). Barriers to the development of livestock in Bangladesh.

3. Das BC and Hashim MA (1996). Studies on surgical affections in calves. Bangladesh Veterinary Journal 30:53-57.

4. Healey KAE, Dawson S, Burrow R, Cripps P, Gaskell CJ, Hart CA, Pinchbeck, GL, Radford AD and Gaskell RM (2007). Prevalence of feline chronic gingivo-stomatitis in first opinion veterinary practice. Journal of Feline Medicine and Surgery 9: 373-381.

5. Islam MS, Khan MSI, Kader HA, Begum MR and Asgar MA (2012a). Prevalence of PPR of goat and their response to antibiotic treatment at Mirzaganj Upazila of Patuakhali Distrtict. Journal of Environmental Science and Natural Resources 5: 181-184.

6. Islam Z, Alam MZ, Akter S, Roy BC and Mondal MMH (2012b). Distribution patterns of vector snails and trematode cercaria in their vectors in some selected areas of Mymensingh. Journal of Environmental Science and Natural Resources 5: 37-46.

7. Kabir MH, Reza MA, Razi KMA, Parvez MM, Bag MAS and Mahfuz SU (2010). A report on clinical prevalence of diseases and disorders in cattle and goat at the Upazilla Veterinary Hospital, Ulipur, Kurigram. International Journal of Biological Research 2: 17-23.

8. Karim Z, Huque KS and Ali Z (2010). Growth and Development Potential of Livestock and Fisheries in Bangladesh. Bangladesh Food Security Investment Forum, 26-27 May 2010, Dhaka.

9. Khair A, Alam MM, Rahman AKMA, Islam MT, Azim A and Chowdhury EH (2013). Incidence of reproductive and production diseases of cross-bred dairy cattle in Bangladesh. Bangladesh Journal of Veterinary Medicine 11: 31-36.

10. Mia MAR (2013). Final Draft National Livestock Extension Policy.

11. Osmani ABMMG, Hossain MA, Rahman MM and Alam MR (2000). Corneal opacity in cattle: Prevalence and therapeutic evaluation of certain drugs. Bangladesh Veterinarian 17: 42-45.

12. Onneshan U (2014). Recent Trends of Growth in Agriculture, Industry and Power Bangladesh Economic Update.

13. Pallab MS, Ullah SM, Uddin MM and Miazi OF (2012). A cross sectional study of several diseases in cattle at Chandanaish Upazilla of Chittagong district. Scientific Journal of Veterinary Advances 1: 28-32.

14. Pharo HJ (1987). Analysis of clinical case records from dairy co-operatives in Bangladesh. Tropical Animal Health and Production 19: 136-142.

15. Rahman MM, Ali M and Hashem A (1999). Livestock disease problems in a selected area of Sherpur district. Bangladesh Journal of Training and Development 12: 205-210.

16. Rahman MA, Islam MA, Talukder AK, Parvin MS and Islam MT (2012). Clinical diseases of ruminants recorded at the Patuakhali Science and Technology University Veterinary Clinic. Bangladesh Journal of Veterinary Medicine 10: 63-73.

17. Samad MA (2001). Observations of clinical diseases in ruminants at the Bangladesh Agricultural University Veterinary Clinic. Bangladesh Veterinary Journal 35: 93-120.

18. Samad MA (2011). Public health threat caused by zoonotic diseases in Bangladesh. Bangladesh Journal of Veterinary Medicine 9: 95-120.

19. Samad MA, Islam MA and Hossain A (2002). Patterns of occurrence of calf diseases in the district of Mymensingh in Bangladesh. Bangladesh Veterinary Journal 36: 01-05.

20. Sarker MAS, Hashim MA, Rahman MB and Begum H (1999). Studies on bovine lymphadenitis syndrome. Bangladesh Veterinarian 10: 6-8.

21. Sarker MAS, Aktaruzzaman M, Rahman AKMA and Rahman MS (2013). Retrospective study of clinical diseases and disorders of cattle in Sirajganj District in Bangladesh. Bangladesh Journal of Veterinary Medicine 1: 137-144. 